IIUC STUDIES

ISSN 1813-7733

Vol.-12 December 2015

(P. 139-146)

\title{
Of Motivation and Learning English: A Perspective on EFL Students in Bangladesh
}

\author{
SM Akramul Kabir ${ }^{1}$
}

\begin{abstract}
Motivation and learning tend to be interrelated with each other. Among all other learning variables, motivation is considered the most significant factor in language learning. The More a learner is motivated the more effective learning takes place. Learning a foreign language such as English denotes the preference and zeal of the learner depending on the intensity of motivation. So, in order to help the students to maintain proper strength in English, learning motivation is essential for the teachers in regular teaching procedure. This paper discusses the role of motivation for English language learning in four main sections focusing on EFL students of Bangladesh. Finally, some suggestions are offered to the teachers.
\end{abstract}

Key words: motivation,learning English,EFL learners, classroom context, rudimentary suggestions.

\section{Introduction about motivation}

In the last two decades, researchers in the field of language learning have identified the importance of motivation for successful foreign or second language learning (Gardner, 1985; Tremblay \& Gardner, 1995; Wharton, 2000;Noels, 2001). Motivation actually determines what we can do or enhances our ability to do. So, it is the driving force for doing things. There are different variables influencing and affecting Second Language Acquisition. Among these factors, motivation has received more attention in language learning than any other single factor in individual differences (Ellis, 2008). Therefore, it is acknowledged that motivation is one of the most important factors influencing learners' English achievements. It has also a close relationship with students' success and failure in teaching English. Moreover, Gardner (1985) denotes that motivation for language learning can include both goal orientation and the combination of effort that creates desire to achieve

\footnotetext{
1 Lecturer, Department of English, Chittagong College, National University of Bangladesh
} 
the goal of learning the language. His core of motivation is the dichotomy of integrative and instrumental orientations. However, Ellis (2008) claims that Instrumental Motivation is not contrary to Integrative Motivation rather it works in conjunction with Integrative Motivation. Although a huge disagreement to the impact of the kinds of motivation exists on the English learning performance, Gardner gives a significant impetus to the development of the motivation theory.

Nonetheless, all the language researchers in the world do not agree with Gardner's view of motivation. Hungarian psychologist Dornyei (1994) suggests a motivation model viewing motivation as an intricate process with three levels: the language level, the learner level, and the learning situation level. On the contrary, Brown (1994) has classified the motivation into three types, such as global motivation, situational motivation, and task motivation respectively. Subsequently, Wen (2001) illustrates motivation as the cause for studying English and the target of learning English. She identifies two types motivation in learning English: surface motivation and deep motivation. Those who have surface motivation are inclined to get a degree, a better job, or a higher salary. On the other hand, those who have deep motivation are interested to learn English for great interest and for the expansion of their knowledge.

\section{Instrumental and Integrative motivation}

The most extensive and longitudinal research into the role of motivation in L2 learning has been conducted by Gardner \& Lambert (1972). These two researchers extensively studied SFL (Spanish as a Foreign Language) learners in Canada, several parts of the United States, and the Philippines to give a fair endeavour to recommend how attitudinal and motivational factors affect language learning success over a period of twelve years. They examined motivation as a factor relating to different kinds of attitudes, and two different clusters of attitudes are divided into two types of Motivation: Instrumental and Integrative motivation. Instrumental Motivation indicates the desire to achieve a new language for utility and Integrative Motivation denotes the desire to achieve proficiency in a new language for the reason to involve in the social life of the TL community. In addition, to the study by Gardner and Lambert, several empirical studies by different researchers also provide evidence that both types of motivation have positive effects on the achievement level of proficiency by different learners and one type may be more 
Of Motivation and Learning English: A Perspective on EFL Students in Bangladesh

productive than the other under specific conditions. Dornyei \& Otto (1998) have also mentioned that motivation does not remain static rather it is dynamic and its entity always evolves and changes from time to time. At present, English is considered in Bangladesh as a utilitarian tool for trade and commerce, science and technology, national development and modernization as well as a crucial element in furthering a career. A lot of students pay attention to learning English with Instrumental Motivation. A significant number of them are quite successful in increasing proficiency of English with Integrative Motivation. This indicates that the relative importance of Instrumental or Integrative motivation depends to a large extent on the context in which a new language is learned.

\subsection{Language level, Learner level and Situation level}

Dornyei (1994) in his study defines framework for motivation that comprises three levels: the language level, the learner level, and the learning situation level. These three levels of learning motivation are connected respectively to the social dimension, the personal dimension, and the educational subject matter dimension. He explains that the language level focuses on motives and orientations related to diverse aspects of language, such as how it carries the culture, the milieu where it is spoken, and the potential necessity of proficiency in it. The learner level focuses on a synthesis of affects and cognitions to form fairly static personality traits to increase learner's self-confidence and learning goals. The learning situation level consists of intrinsic and extrinsic motivational conditions, focuses on the syllabus, the teaching materials, the teaching methods, and the learning tasks.

\subsection{Global, situational and task motivation}

Brown (1994) conducts another research on motivation. In his research, he has differently identified three types of motivation: global, situational and task motivation. Global motivation comprises a general orientation to the aim of learning a new language. Situational motivation denotes the favorable influences generating from the learning conditions, and it varies in accordance with the situation in which learning takes place. Task motivation is the impetus for performing particular learning tasks, for instance, the students will gradually increase a liking for second or foreign language learning if the teacher designs pertinent tasks to lead them to successful performances. 


\section{Role of Motivation in EFL in Bangladesh}

Although there has been an increasing awareness and interest among language researchers and teachers simultaneously in the role of motivation in EFL, the concepts of integrative and instrumental motivational orientations and their implications in learning English as foreign language appear to be too limited to describe in Bangladesh scenario. Rukanuddin (2014) posits that the role of motivation in Bangladesh is different from other countries as students learn English only for instrumental motivation and integrative motivation is almost irrelevant due to the contextual and cultural reasons. For this reason, that majority of the students in Bangladesh learn English from the perspective of instrumental motivation with the purpose of easing their education and getting better employment and career opportunities both in home and abroad. However, Bangladeshi students studying in Australia, Canada, United Kingdom and United States, with an intention to settle permanently in those areas, learn English with integrative motivation although their percentage is not significant $(10.32 \%)$ in comparison to instrumental motivation (80.26\%) (Rukanuddin,2014). Moreover, According to Hussain \& Masum (2016), "students learn English language for practical reason i.e. get a good score in public exams, securing a good job, getting opportunities for higher education and so on" (p. 185).

Therefore, it is acknowledged that most of the students of Bangladesh possess instrumental kind of motivation for learning English. Furthermore, a major part of students want to improve their professional prospects. These students have high instrumental motivation to learn English well, because a good competency of English will help them more considerably to get good jobs in companies or joint ventures having international exposure, to read technical materials, and to study abroad. Still, others are interested in the learning environment or encouraged by their previous success. These students have task and situational motivation. A few of them are interested by the target culture as they are integrally motivated. Moreover, this section of students is attracted to adopt modern and western life style. 
Of Motivation and Learning English: A Perspective on EFL Students in Bangladesh

Although the teaching and learning of English as EFL in Bangladesh is common but is still an intricate issue for students. They are taught to learn English to pass examinations, and to get a good job in future. Till now, the reasons for motivation towards learning English language are mainly instrumental. However, one of the important factors that restricts motivation of students is the prevailing Testing System that does not comprise speaking and listening skills of students. Due to this fact, institutions appear to have no objective of preparing learners for overall linguistic/communication skills. Certainly, a huge number of learners represent the core reason for learning English as a requirement for successfully passing the examinations. Therefore, it is suggested that institutional system of examination must be designed in such a way that it will work as a source of motivation for students to learn English. Since most of the students are never without motivation, the problem which deserves our attention is not to motivate students to learn English, but to improve their present motivation to learn it well. At this point, the author intends to suggest some principles that can improve the present situation of English language teaching and learning process.

\section{Rudimentary recommendations to the enhancement of students' motivation}

\subsection{The student-centric class}

In Bangladesh, every level of English teaching follows a prescribed syllabus focusing on ESP. Although the learning levels of English are different, one thing is common to all the learners, irrespective of levels, that they require to read and understand texts or teaching materials related to their syllabus to pass their relevant examinations. The teachers also teach the relevant elements to the students making the classroom one way traffic where only Dramatic Monologue takes place. Therefore, there is no scope for peer discussion or teacher-student interaction in the classroom. Only Motivation can create activity-based and interactive language classroom to change the traditional rote-learning culture.

Tudor (2001) points out that language classroom is a "complex adaptive system". He claims that although the physical features of most classrooms are same, each classroom has a unique environment due to the participation of individuals in teaching and learning and the culture 
that they bring in it. This idea scaffolds that the classroom, is the central place where language learning process takes place. That is why, only in a student-centric classroom students will have motivation to involve themselves in classroom activities to learn the language. Therefore, instead of giving directions to students to memorize the rules of target language and learn vocabulary by heart, the teacher should introduce some elements from communicative approach, that is, providing students with enough opportunities to practice the new language and learn how to use it in actual context. Without dominating students in the classroom, the teacher should initiate some questions for them to communicate following IRF sequence that will encourage them to ask and discuss each other, or even to argue about with each other on some debatable issues of language. Within the duration of teaching, the teacher should present an element of challenge to the students, and the challenge can lead to higher motivation resulting more effective and pragmatic language learning. In this regard, student-centric classroom is more conducive to generate this process.

\subsection{Coherence of Teaching approach and testing is needed}

In Bangladesh, Communicative Language Teaching (CLT) approach has already been in practice over a decade in teaching English and the syllabi are designed in accordance with this approach. However, the Testing System has been and is conventional form of assessment rather than Performance based assessment which is being criticized in recent time for its fiasco to truly assess students' language learning outcomes. According to Chen and Martin (2000), conventional form of assessment is incoherent to CLT approach as it cannot assess four integrative skills of a language. Since we follow Traditional assessment for Language Testing, we ignore speaking and listening skills. Moreover, Traditional assessment is not well adapted to measure learner's application of content knowledge, their capacity to synthesise content knowledge through subject areas, and their capabilities to communicate, to cooperate, and to perform linguistic competence accordingly (McTighe \& Ferrara, 1996). Therefore, the students can be better motivated if they are assessed for all four integrative skills and the learning focus is given 
Of Motivation and Learning English: A Perspective on EFL Students in Bangladesh

to performance and creativity rather than rote memorization and passing examination.

\subsection{Encouraging students accordingly}

Learning English is an exhaustive task. Encouragement and praise should be treated as a reward for learning it. We all know that to learn a new language well, such as English, is no easy job for the majority of students. It needs countless practice and great effort. If students' hard work and progress are ignored by the teachers, they may feel disappointed, or even become demotivated. On the contrary, if the teachers praise students' effort and progress timely, they will extend more efforts and consequently will make greater progress in learning English. Many teachers have had experience of occasionally encouraging or praising a student who is having great difficulty in learning English, and in the end, to everybody's surprise, the student becomes enthusiastic about learning English resulting in a considerable progress.

\section{Conclusion}

Dornyei (1994, 1998) suggests that L2 learning motivation is a multifaceted construct which has no absolute definition. Recent research has taken more account of situation-specific factors impacting on language learning experience. Moreover, at present, L2 motivation is increasingly viewed as a 'dynamic' rather than a 'static 'concept; that means motivation does not remain stable all the time. Noels (2001) suggests that motivational orientations in second or foreign language learning can be categorized according to the extent to which the goal for performing an activity is self-determined. For this reason, L2 learning motivation is a concept with much different aspects that are relevant per se. Therefore, it is stressed on the point that motivation is crucial but not the only factor which influences learner's second or foreign language proficiency. Other factors, such as aptitude, the role of age, role of first language, personality and learning styles in SLA, learner strategies, formal instruction, learning cognitive style, also play vital roles on a new language learning process. The above mentioned suggestions will help English teachers to gain more effective approaches to English teaching in classroom in order to improve students' English proficiency. 


\section{References}

Brown, D. H. (1994). Principles of language learning and teaching ( $3^{\text {rd }}$ ed.). Prentice-hall Inc.

Chen, Yih-Fen, \& Martin, Michael A. (2000). Using performance assessment and portfolio assessment together in the elementary classroom. Reading Improvement, 37 (1), 32-38.

Dornyei, Z. (1994). Motivation and motivating in the foreign language class room. Modern Language Journal, 78 (3), 273-284.

Dornyei, Z. (1998) Motivation in second and foreign language learning. Language Teaching, 31, 117-135.

Dornyei, Z.,\&Ottố (1998). Working papers in Applied Linguistics, Thames Valley University, London, 4, 43-69.

Ellis, R. (2008). The Study of second Language Acquisition ( $2^{\text {nd }}$ ed.).Oxford: Oxford Press.

Gardner, R. C. \& Lambert, W. E. (1972). Attitudes and motivation in second language learning. Rowley, Mass.: Newbury House.

Gardner, R. C. (1985).Social psychology and second language learning. London: Arnold.

Hussain, Z. \& Masum, MD. Z. (2016). Motivation of Bangladeshi Higher Secondary Students in Learning English Language. Language in India, 16 (2), 177-189.

McTighe, J., \& Ferrara, S. (1996). Performance based Assessment in the classroom: A planning Framework. In R.E. Blum \& J.A. Arter (Eds).

Noels, K. A. (2001). Learning Spanish as a second language: learners' orientations and perceptions of their teachers' communication style. Language Learning, 51, 107-144.

Rukanuddin, M. (2014). Role of Motivation on the Tertiary Level Students of Bangladesh in Learning English. Research on Humanities and social Sciences, 4 (27), 76 -100.

Tremblay, P. F., \& Gardner, R. C. (1995). Expanding the motivation construct in language. The Modern Language Journal, 79(4), 505-518.

Tudor, I. (2001).The dynamics of the language classroom. Cambridge: Cambridge University Press. learning.

Wen Qui-fang. (2001). Applied Linguistics: Research methods and thesis writing. Foreign Language Teaching and Research Press.

Wharton, G. (2000). Language Learners in Singapore. Language Learning, 50, 203-243 